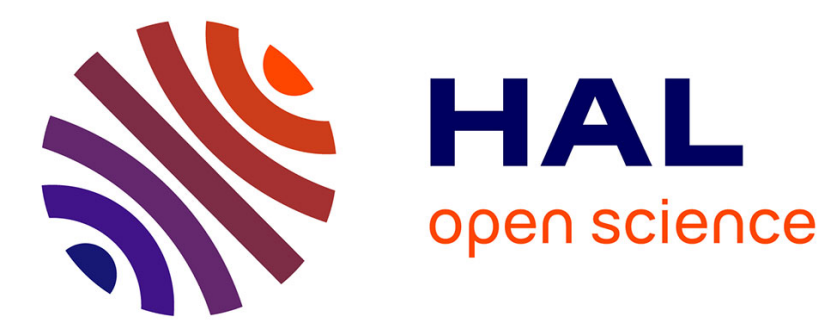

\title{
ACOUSTIC BEHAVIOUR OF NORMAL AND DENSIFIED VITREOUS GeO2
}

Giovanni Carini, Laura Orsingher, Gaspare Tripodo, Edmondo Gilioli

\section{To cite this version:}

Giovanni Carini, Laura Orsingher, Gaspare Tripodo, Edmondo Gilioli. ACOUSTIC BEHAVIOUR OF NORMAL AND DENSIFIED VITREOUS GeO2. Philosophical Magazine, 2008, 88 (33-35), pp.4143-4150. 10.1080/14786430802247205 . hal-00513916

\section{HAL Id: hal-00513916 https://hal.science/hal-00513916}

Submitted on 1 Sep 2010

HAL is a multi-disciplinary open access archive for the deposit and dissemination of scientific research documents, whether they are published or not. The documents may come from teaching and research institutions in France or abroad, or from public or private research centers.
L'archive ouverte pluridisciplinaire HAL, est destinée au dépôt et à la diffusion de documents scientifiques de niveau recherche, publiés ou non, émanant des établissements d'enseignement et de recherche français ou étrangers, des laboratoires publics ou privés. 


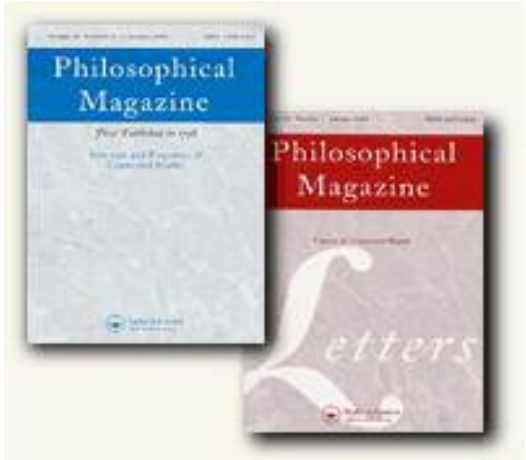

\section{ACOUSTIC BEHAVIOUR OF NORMAL AND DENSIFIED VITREOUS GeO2}

\begin{tabular}{|c|c|}
\hline Journal: & Philosophical Magazine \& Philosophical Magazine Letters \\
\hline Manuscript ID: & TPHM-08-May-0159 \\
\hline Journal Selection: & Philosophical Magazine \\
\hline $\begin{array}{r}\text { Date Submitted by the } \\
\text { Author: }\end{array}$ & 15-May-2008 \\
\hline Complete List of Authors: & $\begin{array}{l}\text { Carini, Giovanni; Dip. Fisica, Università di Messina } \\
\text { Orsingher, Laura; Università di Trento, Fisica } \\
\text { Tripodo, Gaspare; Università di Messina, Fisica } \\
\text { Gilioli, Edmondo; IMEM del CNR }\end{array}$ \\
\hline Keywords: & internal friction, soft matter \\
\hline Keywords (user supplied): & internal friction, soft matter \\
\hline
\end{tabular}

\section{(5) ScholaroNE \\ Manuscript Central}




\title{
Acoustic behaviour of normal and densified vitreous $\mathrm{GeO}_{2}$
}

\author{
Giovanni Carini Jr†, Laura Orsingher $\neq$, Gaspare Tripodo†, Edmondo Gilioli§ \\ †Dipartimento di Fisica, Università di Messina, Salita Sperone 31, I-98166 Messina, Italy \\ $\ddagger$ Dipartimento di Fisica, Università di Trento, 38100 Povo (TN), Italy. \\ §IMEM del C.N.R., Area delle Scienze, 43010 Parma, Italy
}

\begin{abstract}
The acoustic properties of $\mathrm{GeO}_{2}$ glass were investigated by measuring the acoustic attenuation and the sound velocity between 1.5 and $300 \mathrm{~K}$ over the frequency range between 10 and $50 \mathrm{MHz}$. A low-temperature plateau of attenuation followed by a large loss peak, which is paralleled by a corresponding dispersive behaviour of the sound velocity, represent the main characteristics of the experimental observations. The temperature behaviour of ultrasonic attenuation has been explained in terms of thermally activated relaxations of intrinsic structural defects at high temperatures $(\mathrm{T}>10 \mathrm{~K})$ and of tunnelling motions at low temperatures $(\mathrm{T}<10 \mathrm{~K})$. A direct comparison between the values of the tunnelling strength obtained over the $\mathrm{MHz}$ and $\mathrm{kHz}$ intervals indicates that the internal-friction plateau arising from the phonon-assisted tunnelling of two-level systems (TLS) is slightly frequency dependent. The analysis of the temperature dependence of the sound velocity shows that the anomalous hardening, typical of glasses having tetrahedrally coordinated structures, starts above about $100 \mathrm{~K}$. Finally the comparison of the sound velocity behaviour in normal and permanently densified $\mathrm{GeO}_{2}$ glasses evidences that densification leads to a significant reduction of the number of relaxing particles.
\end{abstract}

\section{INTRODUCTION}

The attenuation and the velocity of sound waves in glasses are an important subjects mainly because distinct and competing mechanisms are responsible for the behaviour observed over different temperature and frequency ranges[1-4]. In particular, the origin and the nature of low-energy excitations, which are responsible of anomalies in the acoustic properties of 
glasses [5, 6], is a central question in the physics of disordered solids. These excitations are usually accounted for by local motions of localized structural defects. The tunnelling model $[7,8]$ associates these defect modes to single atoms or groups of atoms subjected to quantummechanical tunnelling between two different stable positions available in the glassy network and schematizes the locally mobile "particles" by asymmetric double-well potentials. A more recent extension of the tunnelling model $[1,9]$ includes the case of a strong coupling between tunnelling two-level systems (TLS) and phonons and individuates three temperature regions where different mechanisms are regulating the motion within the two wells and the related acoustic properties: coherent tunnelling at low temperatures $(\mathrm{T}<5 \mathrm{~K})$, incoherent tunnelling at intermediate temperatures $(5 \mathrm{~K}<\mathrm{T}<20 \mathrm{~K})$ and thermally activated jumps over the potential barrier at higher temperatures $(\mathrm{T}>20 \mathrm{~K})$. This theoretical approach covers both tunnelling and classical activation, leading to a coherent description of the acoustic behaviour of glasses over the wide range from very low to room temperature. It has been proved, in fact, that theoretical evaluation of the sound attenuation in the $\mathrm{kHz}$ range permits with acceptable agreement the reproduction of the behaviour observed in glassy prototypes, such as $\mathrm{B}_{2} \mathrm{O}_{3}$ and $\mathrm{GeO}_{2}$ [1]. In this manuscript, we report a study concerning the temperature dependence of the acoustic attenuation and sound velocity at $\mathrm{MHz}$ frequencies in glassy $\mathrm{GeO}_{2}$, in order to investigate the frequency dependence of the mechanisms governing the acoustic behaviour at low and high temperatures. Moreover the temperature dependence of the sound velocity was measured in a permanently compacted $\mathrm{GeO}_{2}$ glass $\left(\rho=4.52 \mathrm{~g} / \mathrm{cm}^{3}\right)$, in order to investigate the effects of densification on thermally activated relaxations. One of the most striking results is that the permanent densification of a glass markedly depresses the local mobility of structural defects.

\section{EXPERIMENTAL DETAILS}

Vitreous germania $\mathrm{GeO}_{2}$ was prepared by melt-quenching and then the glass was annealed and stabilized at about $830 \mathrm{~K}$ (about $20 \mathrm{~K}$ below its calorimetric glass transition temperature $\mathrm{T}_{\mathrm{g}}$ ) in a high-purity nitrogen atmosphere in order to avoid undesired effects arising from thermal history on the observed acoustic behaviour and then cooled and stored at room temperature. Some cuts of the same sample were successfully densified by a multi-anvil HT\&HP apparatus. 
They were compressed at $6 \mathrm{GPa}$ and heated under pressure at $673 \mathrm{~K}$ for 2 minutes resulting in a mass density of $4.52 \mathrm{~g} / \mathrm{cm}^{3}$. A typical raw sample had both diameter and a length of $6 \mathrm{~mm}$ Longitudinal sound waves were obtained by tuning X-cut quartz crystals at their fundamental frequency. The attenuation and velocity of longitudinal ultrasound were measured using an apparatus described elsewhere [10], based on the pulse-echo overlap technique and the correct echo overlap, for sound velocity measurement, was obtained by using the $\Delta \mathrm{T}$ McSkimin criterion [11]. The sample-transducer bonding agent was N-Apiezon grease. A correction to take into account the bond was not carried out, but a rough evaluation of the corresponding error introduced in the velocity was less than $0.05 \%$.

The thermal scanning between 1.5 and $300 \mathrm{~K}$ was carried out by using a standard liquid helium cryostat in the range between 1.5 and $20 \mathrm{~K}$ and a cryogenerator above $10 \mathrm{~K}$. The thermostatic control was better than $0.1 \mathrm{~K}$ in the whole temperature range. The density was measured at room temperature by a Micrometrics Accupyc 1300 gas pycnometer under helium gas, having an accuracy of $0.03 \%$

\section{RESULTS AND DISCUSSION}

\subsection{Acoustic attenuation}

Figure 1a reports the attenuation of ultrasonic waves of frequencies in the range from $10 \mathrm{MHz}$ to $50 \mathrm{MHz}$ as a function of temperature between 1.5 and $300 \mathrm{~K}$ in glassy $\mathrm{GeO}_{2}$. A more useful comparison of the acoustic loss obtained over an extended interval of frequencies is obtained by transforming the attenuation into the internal friction $\mathrm{Q}^{-1}\left(=0.23 \alpha_{\mathrm{db}} V / \omega\right.$, where $\alpha_{\mathrm{db}}$ is the attenuation in $\mathrm{db} / \mathrm{cm}, V$ the sound velocity and $\omega$ the angular frequency). The temperature behaviour of $\mathrm{Q}^{-1}$ at 10 and $50 \mathrm{MHz}$ is reported in figure $1 \mathrm{~b}$. With increasing temperature the attenuation rises until it reaches a plateau which extends up to about $10 \mathrm{~K}$. At higher temperatures, the attenuation increases up towards a broad peak, whose maximum shifts to 


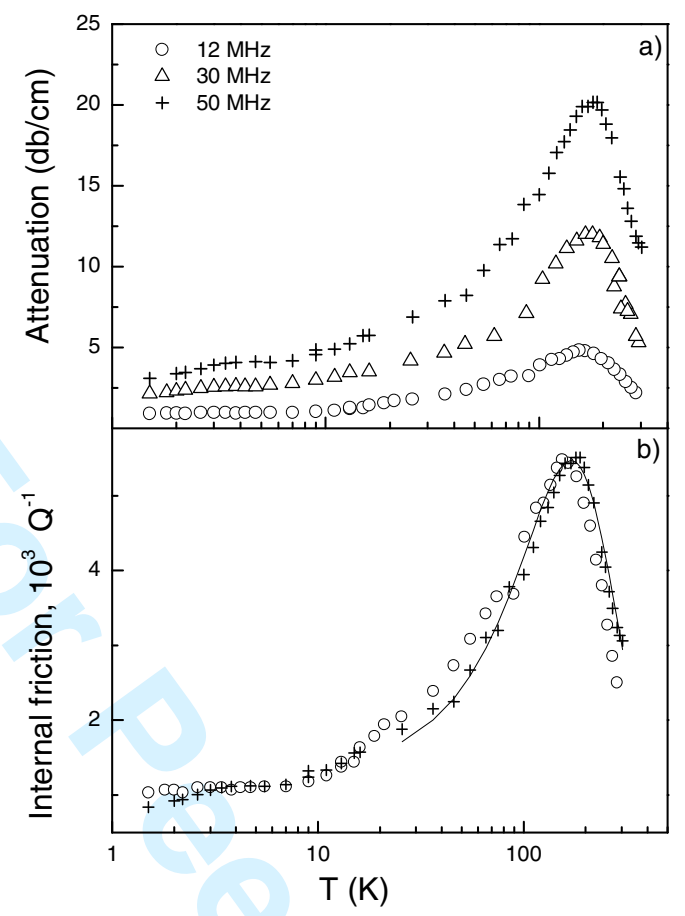

Figure 1. (a) The temperature dependence of the attenuation of longitudinal ultrasonic waves at $10(\mathrm{O})$, $30(\Delta)$ and $50(+) \mathrm{MHz}$ in $\mathrm{GeO}_{2}$ glass. (b) Comparison between the experimental data for the internal friction $\mathrm{Q}^{-1}$ at $10(\mathrm{O})$ and $50(+) \mathrm{MHz}$ in $\mathrm{GeO}_{2}$ glass. The solid line is the theoretical fit of relaxation loss at $50 \mathrm{MHz}$ by the ADWP model (Eq. 2).

higher temperatures as the ultrasonic driving frequency is increased. These observations imply that, in the temperature range above about $20 \mathrm{~K}$, the acoustic behaviour is governed by thermally activated relaxations of structural defects, characterized by a distribution of relaxation times $\tau$ as a consequence of the inherent randomness of the glassy topology.

The low-temperature plateau of internal friction, whose onset shifts to higher temperatures with increasing frequency (see figure $1 b$ ), has been explained in terms of phonon-assisted tunnelling of two level systems (TLS) and is directly related to the tunnelling strength $C_{i}[1$, 12]:

$$
Q_{i, \text { plateau }}^{-1}=\frac{\pi}{2}\left[\frac{\bar{P} \gamma_{i}^{2}}{\rho V_{i}^{2}}\right]=\frac{\pi}{2} C_{i}
$$

Here $V_{i}$ is the ultrasonic wave velocity, $\gamma_{i}$ the deformation potential that expresses the coupling between the ultrasonic stress and the system, $\bar{P}$ the TLS spectral density, $\rho$ the sample density and the index $i$ refers to the different polarizations ( $l$ stands for longitudinal and $t$ for transverse). A background of ultrasonic loss, which is temperature independent but frequency dependent, has been discarded using the procedure described in detail in Ref. 13. The calculated value of the tunnelling strength $C_{l}$ is $4.17 \times 10^{-4}$. This value is very close to that 
$\left(C_{l}=4 \times 10^{-4}\right)$ obtained in a previous study, carried out in the $\mathrm{MHz}$ interval and at temperatures below $10 \mathrm{~K}$ [14], but slightly higher than the value determined at $\mathrm{kHz}$ frequencies $(C=2.38 \times$ $10^{-4}$ ) [1]. At variance with the theoretical expectation of the tunnelling model provided by Eq. (1), this result emphasizes that the internal-friction plateau results to be slightly frequency dependent, as already observed for glassy $\mathrm{SiO}_{2}$ and polymethylmethacrylate (PMMA) [15].

Above the region of the plateau, the internal friction exhibits a maximum associated to thermally activated relaxations of structural defects over the potential barriers (in a schematic representation of the defects by double-well potentials). A contribution to the increase of $Q^{-1}$ between about 8 and $20 \mathrm{~K}$, i.e. the region between the plateau and the loss peak, can arise from incoherent tunnelling effects within the two wells as a consequence of increasing thermal motion which prevents the phase coherence of the TLS tunnelling motion [1]. Limiting the present analysis to the temperature region above $20 \mathrm{~K}$ where only the relaxation process is dominant, the loss peak can be described by the asymmetric double-well potential (ADWP) model, following the procedure described by Gilroy and Phillips [14]. Barrier heights $V$ varied randomly over the defect sites with Gaussian distribution, $g(V)=\frac{1}{\sqrt{2 \pi}} V_{0}^{-1} \exp \left[-\frac{\left(V-V_{m}\right)^{2}}{2 V_{0}^{2}}\right]$, and asymmetries $\Delta$ having a constant spectral density, $f(\Delta)=f_{0}$, have been used. In the GP framework, the relaxation time $\tau$ of the process has been approximated by the usual Arrhenius law, $\tau=\tau_{0} e^{V / k_{B} T}$, where $V$ is the activation energy of the process and $\tau_{0}$ the characteristic time, related to the vibrational frequency of the relaxing defect in a single well. It results the following expression which accounts for the temperature dependence of the acoustic loss [16]:

$$
Q^{-1}=2\left(\frac{f_{0} \gamma_{l}^{2}}{\rho V^{2}}\right) \int \frac{\omega \tau}{1+\omega^{2} \tau^{2}} g(V) d V
$$

where $\left(\frac{f_{0} \gamma_{l}^{2}}{\rho V^{2}}\right)=C^{*}$ is the relaxation strength. By numerical evaluation of the experimental data, the following values of the relaxation parameters have been obtained: $C^{*}=3.73 \times 10^{-2}$, $V_{o} / k_{B}=1157 \mathrm{~K}, \mathrm{~V}_{\mathrm{m}}=1245 \mathrm{~K}$ and $\tau_{o}^{-1}=2.65 \times 10^{13} \mathrm{~s}^{-1}$. A typical fit of the relaxation loss, reproducing quite well the shape of the experimental results, is shown by a solid line in Fig. 1b. It is worth emphasizing that, as already observed in borate glasses $[17,18]$, the relaxation strength $C^{*}$ is more than one order of magnitude larger than the tunnelling strength $C$; this large difference being associated with a parallel difference between $f_{o}$ and $\bar{P}$. Assuming that decreasing temperature transforms the mechanisms of local mobility of the same defect states 
from classical activation to tunnelling, this evidence seems to indicate that only a fraction of the relaxing particles are involved in tunnelling local motions.

\subsection{Sound velocity}

In figure $2 \mathrm{a}$, the velocity of $10 \mathrm{MHz}$ longitudinal sound waves is shown as a function of temperature for normal $\mathrm{GeO}_{2}$ glass. Between 1.5 and $240 \mathrm{~K}$ the velocity decreases with increasing temperature exhibiting a slope continuously changing for temperatures varying between about $10 \mathrm{~K}$ and $220 \mathrm{~K}$.

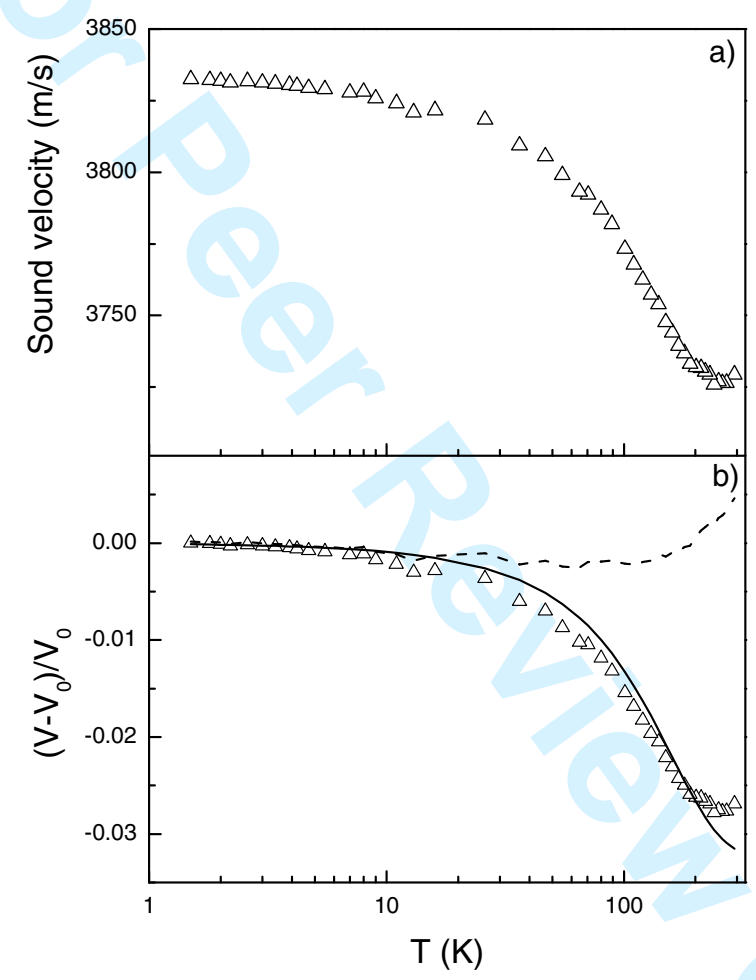

Figure 2. (a) Temperature dependence of the velocity $V(\mathrm{~T})$ of $10 \mathrm{MHz}$ longitudinal sound waves in $\mathrm{GeO}_{2}$ glass. (b) Comparison between the temperature dependence of the experimental fractional sound velocity $\left(V-V_{0}\right) / V_{0}(\Delta)$ of $10 \mathrm{MHz}$ longitudinal ultrasound in $\mathrm{GeO}_{2}$ glass and the relaxation contribution evaluated using Eq. (3) (solid line). The curve reported as dashed line represents the behaviour obtained by subtracting the relaxation contribution from the experimental data of fractional sound velocity.

At about $250 \mathrm{~K}$ the velocity shows a minimum and then begins to increase at even higher temperatures. The temperature dependence of the ultrasonic velocity in glassy $\mathrm{GeO}_{2}$ reflects closely those observed in tetrahedrally bonded glasses, such as $\mathrm{SiO}_{2}$ and $\mathrm{BeF}_{2}$, which show a minimum in the sound velocity over the same temperature range. With respect to the dynamical mechanisms driving the temperature behaviour of the sound velocity, we can 
distinguish three main different regimes: (i) quantum mechanisms having TLSs as mainly responsible below $20 \mathrm{~K}$, (ii) thermally activated relaxations causing the significant drop between 20 and $220 \mathrm{~K}$ and the broad peak observed in the acoustic loss and (iii) a poorly investigated mechanism regulating the positive temperature coefficient observed at even higher temperatures and ascribed to elastic microscopic inhomogeneities [2]. Since the limited temperature interval explored below $20 \mathrm{~K}$ prevents any significant evaluation of processes governing the region (i), a quantitative analysis has been carried out for the temperature region above $20 \mathrm{~K}$. It is worth noting that, in addition to the relaxation process, the vibrational anharmonicity is also expected to contribute significantly to the variation of longitudinal sound velocity $\mathrm{V}_{1}$ between 20 and $300 \mathrm{~K}$. In the above temperature interval the fractional variation of the sound velocity due to the relaxation process can be expressed by the following relation [16]:

$$
\left[\frac{\Delta V_{l}}{V_{l, o}}\right]_{r e l}=-C * \int g(V) \frac{1}{1+\omega^{2} \tau^{2}(V)} d V
$$

where $\Delta \mathrm{V}_{1}=\mathrm{V}_{1}(\mathrm{~T})-\mathrm{V}_{1,0}$ and $\mathrm{V}_{1,0}$ is the sound velocity at the lowest temperature in the experiment.

Using the parameters obtained by the numerical evaluation of the relaxation loss in equation (3) the relaxation contribution to the sound velocity has been evaluated giving the curve shown by a solid line in figure $2 \mathrm{~b}$. Subtraction of this contribution to the experimental data of sound velocity leads to the behaviour shown as a dashed line in the same figure $2 \mathrm{~b}$. It appears clearly that in addition to the slight monotonic decrease of the sound velocity regulated by the vibrational anharmonicity up to about $100 \mathrm{~K}$, there is sudden increase for higher temperatures. This observation shows that the anomalous hardening starts to operate above about $100 \mathrm{~K}$ becoming dominant for higher temperatures. It leads to the positive temperature coefficient of the sound velocity observed for $\mathrm{T}>280 \mathrm{~K}$, in clear contrast with the linear decrease of the elastic constants provided by the vibrational anharmonicity [19, 20].

In figure 3 we have plotted the relative change of sound velocity as a function of temperature of $\mathrm{GeO}_{2}$ densified at $6 \mathrm{GPa}$ in comparison with the experimental data on normal germania glass. The temperature dependences of $\left(\frac{\Delta V_{l}}{V_{l, 0}}\right)$ are very close for both the glasses over the range between $1.5 \mathrm{~K}$ and $75 \mathrm{~K}$ becoming quite different for higher temperatures, where the curve relative to the compacted glass exhibits a significantly smaller slope. Since the behaviour of the sound velocity in glasses below about $20 \mathrm{~K}$ is mainly regulated by tunnelling 


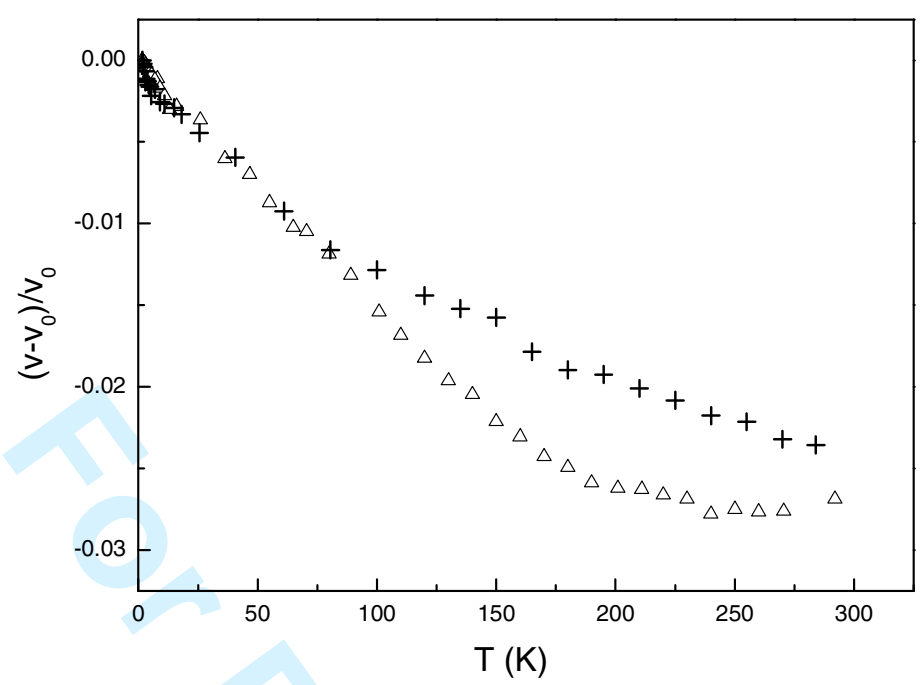

Figure 3. Comparison between the temperature dependence of the fractional sound velocities of 10 $\mathrm{MHz}$ longitudinal ultrasound in normal $(\Delta)$ and permanently densified $(+) \mathrm{GeO}_{2}$ glass.

systems [1], this observation suggests that the glass densification has a small or negligible effect on the mechanisms due to TLSs and operating between 1.5 and $20 \mathrm{~K}$. Quite differently, the strong reduction of the variation of $\left(\frac{\Delta V_{l}}{V_{l, 0}}\right)$ revealed in compacted glass at higher temperatures should be associated to a parallel reduction of the strength of the relaxation process which dominate the velocity behaviour between $20 \mathrm{~K}$ and $300 \mathrm{~K}$ in normal $\mathrm{GeO}_{2}$ glass (see Fig. 2b). In the context of the experimental evidence discussed above which assumes that only the fraction of relaxing particles having lower potential barriers are involved in tunnelling local motions, the present results seem to indicate that the densification process is more efficient in depressing the local mobility of relaxing centres characterized by higher barriers than those experiencing tunnelling motion. It is worth noting that the observations resulting from this preliminary study are in agreement with recent results of Brillouin scattering measurements in a densified silica glass [21]: they showed that thermally activated relaxations become negligible after densification. A more extensive experimental and theoretical study is in progress in order to explain exhaustively the nature of the mechanisms regulating the sound propagation in densified $\mathrm{GeO}_{2}$ glasses. 


\section{CONCLUSIONS}

An ultrasonic study of $\mathrm{GeO}_{2}$ glass performed between 1.5 and $300 \mathrm{~K}$ has revealed that the acoustic attenuation and the sound velocity are mainly regulated by mechanisms having localized motions of atom groups as their microscopic origin. A quantitative analysis of the relaxation loss peaks at high temperatures and of the attenuation plateau due to phononassisted tunnelling of TLS at low temperatures $(\mathrm{T}<10 \mathrm{~K})$ has been performed in terms of defect states schematized by asymmetric double-well potentials. The results suggest that only the fraction of relaxing centres having smaller potential barriers are involved in tunnelling local motions. Comparison between the values of the attenuation plateau obtained over the $\mathrm{MHz}$ and $\mathrm{kHz}$ ranges reveals that it is slightly frequency dependent.

The temperature dependence of longitudinal sound velocity between 20 and $300 \mathrm{~K}$ is mainly regulated by the contributions of thermally activated relaxations and of a hardening of the structure, the latter process beginning above about $100 \mathrm{~K}$ and becoming dominant above 250 $\mathrm{K}$.

Finally the comparison of the sound velocity behaviour in normal and compacted $\mathrm{GeO}_{2}$ glasses over the temperature range between $20 \mathrm{~K}$ and $300 \mathrm{~K}$ leads us to conclude that the local mobility of relaxing particles having higher barrier potentials is severely depressed by densification of the glass. 


\section{REFERENCES}

[1] S. Rau, C. Enss, S. Hunklinger, P. Neu, A. Würger, Phys. Rev. B 527179 (1995)

[2] J. Hertling, S. Baessler, S. Rau, G. Kasper, S. Hunklinger, J. Non-Crystalline Solids 226129 (1998).

[3] J. Fabian and P.B. Allen, Phys. Rev. Lett. 821478 (1999).

[4] P. Benassi, S. Caponi, R. Eramo, et al., Phys. Rev. B 71172201 (2005).

[5] S. Hunklinger and M. v Schickfus, Amorphous Solids ed. by W. A. Phillips (Berlin: Springer 1981) vol 2481.

[6] R. Pohl, X. Liu ,E. Thompson, Rev. Mod. Phys. 74991 and references therein (2002).

[7] P. W. Anderson, B. I. Halperin and C. M. Varma, Phil. Mag. 251 (1972).

[8] W. A. Phillips, J. Low Temp. Physics 7351 (1972).

[9] P. Neu, A. Würger, Europhys. Lett. 27457 (1994).

[10] G.Carini and F. Mento, J. Phys. E 12, 259 (1979).

[11] E. P. Papadakis, Physical Acoustics, ed. by R. N. Thurston and W. M. Mason (Academic, New York, 1976), vol 12277.

[12] J. Jackle, Z. Phys. 257212 (1972).

[13] G. Carini, M. Cutroni, M. Federico and G. Tripodo, Phys. Rev. B 377021 (1988).

[14] C. Laermans, V. Keppens and R. Weeks, Phys. Rev. B 552701 (1997).

[15] K. A. Topp and G. Cahill, Z. Phys. B 101235 (1996).

[16] K. S. Gilroy and W. A. Phillips, Phil. Mag. B43 735 (1981).

[17] G. Carini Jr, G. Carini, G. D’Angelo, G. Tripodo, A. Bartolotta, G. Salvato, Phys. Rev. B 7214201 (2005).

[18] G. Carini Jr, G. Carini, G. D’Angelo, G. Tripodo, A. Bartolotta, G. Salvato, J. Phys. Cond. Matter 1810915 (2006).

[19] J. A. Garber and A. V. Granato, Phys. Rev. B 113990 (1975).

[20] T. N. Claytor and R. J. Sladek, Phys. Rev. B 185842 (1978).

[21] E. Rat, M. Foret, G. Massiera, R. Vialla, M. Arai, R. Vacher, and E. Courtens., Phys. Rev. B 72214204 (2005). 


\section{FIGURE CAPTIONS}

Figure 1. (a) The temperature dependence of the attenuation of longitudinal ultrasonic waves at $10(\mathrm{O}), 30(\Delta)$ and $50(+) \mathrm{MHz}$ in $\mathrm{GeO}_{2}$ glass. (b) Comparison between the experimental data for the internal friction $\mathrm{Q}^{-1}$ at $10(\mathrm{O})$ and $50(+)$ $\mathrm{MHz}$ in $\mathrm{GeO}_{2}$ glass. The solid line is the theoretical fit of relaxation loss at 50 MHz by the ADWP model (Eq. 2).

Figure 2. (a) Temperature dependence of the velocity $V(\mathrm{~T})$ of $10 \mathrm{MHz}$ longitudinal sound waves in $\mathrm{GeO}_{2}$ glass. (b) Comparison between the temperature dependence of the experimental fractional sound velocity $V-V_{0} / V_{0}(\Delta)$ of $10 \mathrm{MHz}$ longitudinal ultrasound in $\mathrm{GeO}_{2}$ glass and the relaxation contribution evaluated using Eq. (3) (solid line). The curve reported as dashed line represents the behaviour obtained by subtracting the relaxation contribution from the experimental data of fractional sound velocity.

Figure 3. Comparison between the temperature dependence of the fractional sound velocities of $10 \mathrm{MHz}$ longitudinal ultrasound in normal $(\Delta)$ and permanently densified (+) $\mathrm{GeO}_{2}$ glass. 
Fig. 1

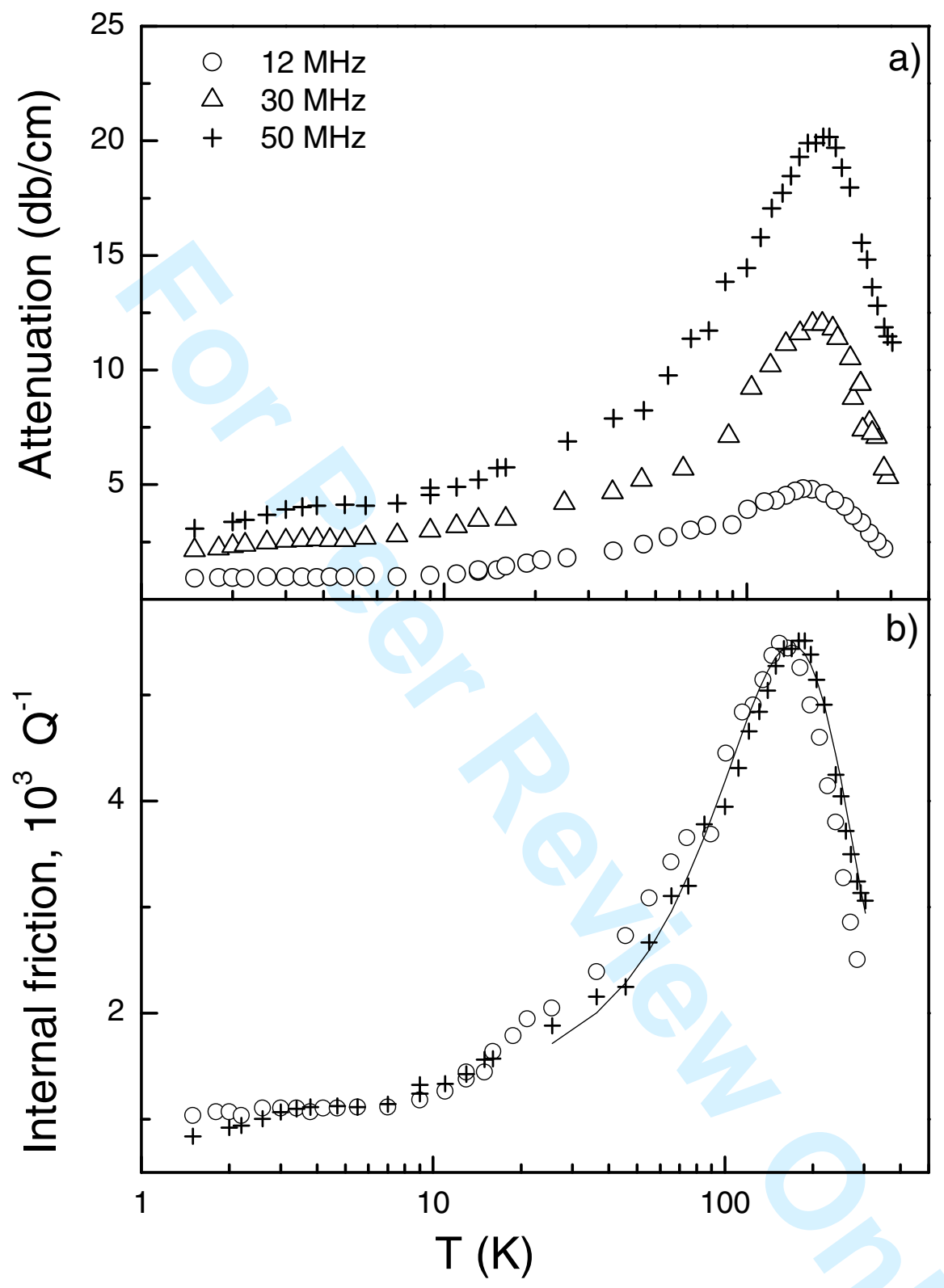


Fig. 2

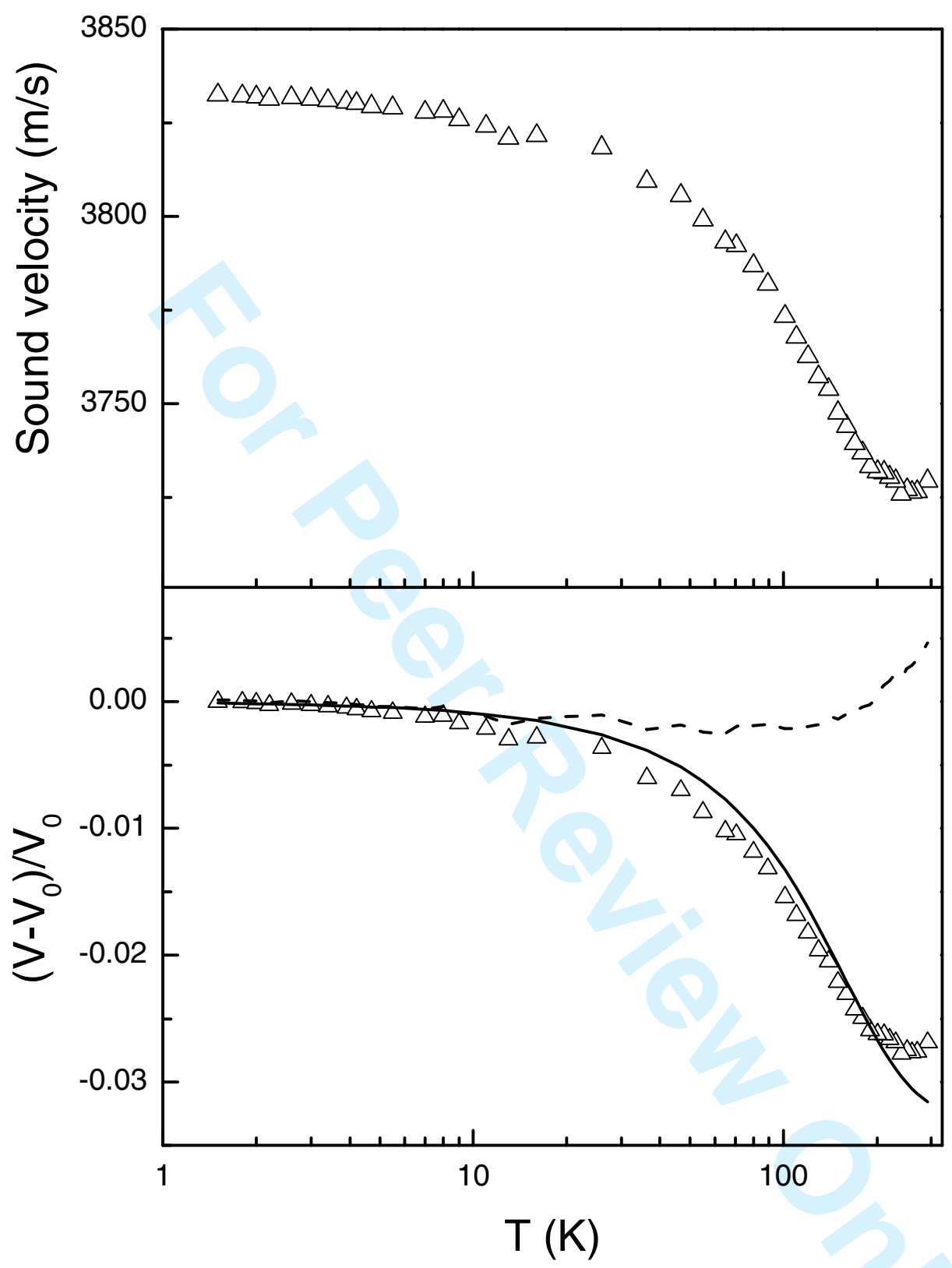


Fig. 3

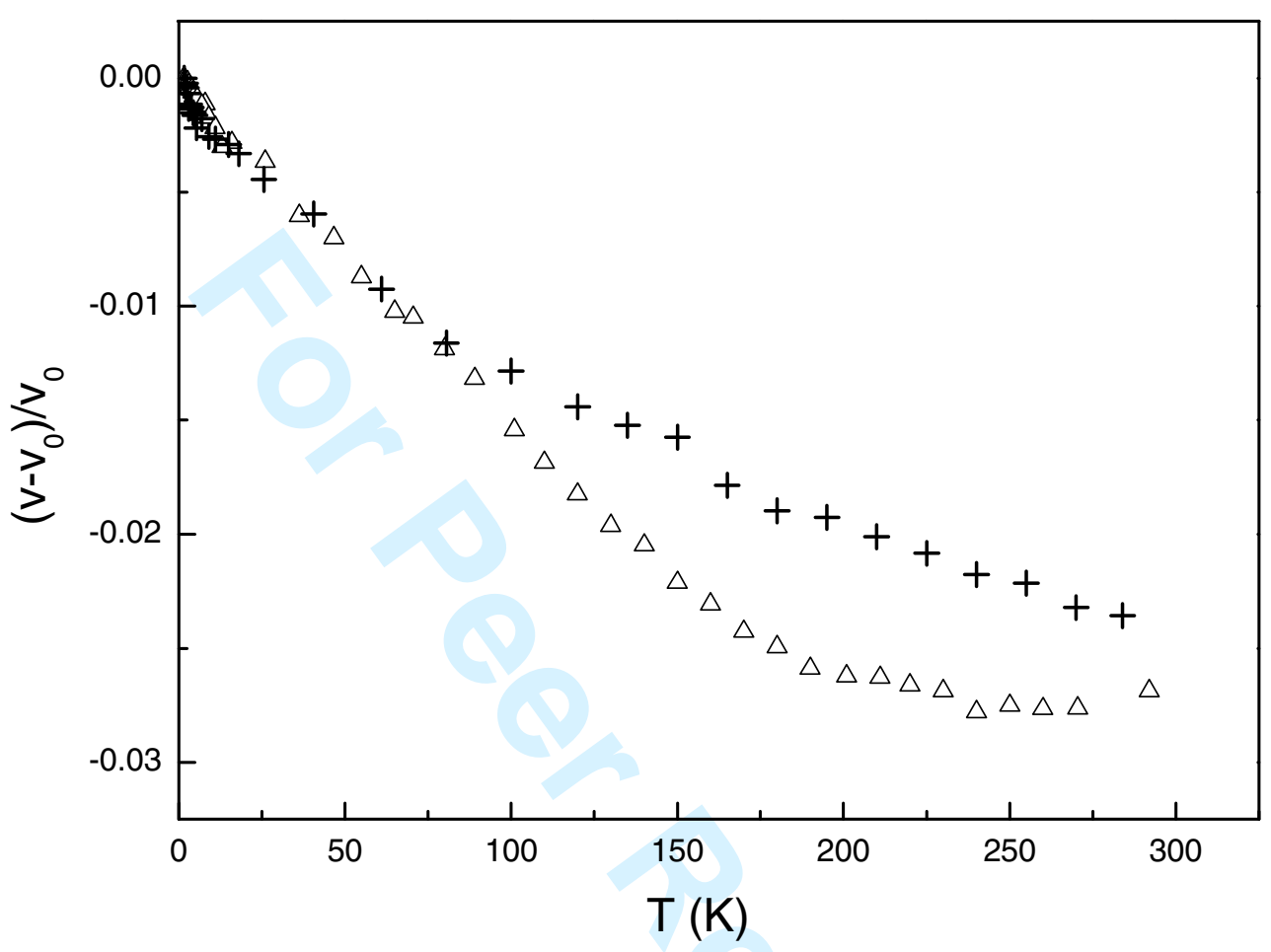

